University of Zurich

Department of Economics

Working Paper Series

ISSN 1664-7041 (print)

ISSN 1664-705X (online)

Working Paper No. 160

\title{
Math Matters: \\ Education Choices and Wage Inequality
}

Andrew Rendall and Michelle Rendall

May 2014 


\title{
Math Matters: \\ Education Choices and Wage Inequality*
}

\author{
Andrew Rendall ${ }^{\dagger}$ and Michelle Rendall ${ }^{\ddagger}$ \\ The University of Zurich
}

May 31, 2014

\begin{abstract}
SBTC is a powerful mechanism in explaining the increasing gap between educated and uneducated wages. However, SBTC cannot mimic the US within-group wage inequality. This paper provides an explanation for the observed intra-college group inequality by showing that the top decile earners' significant wage growth is underpinned by the link between ex ante ability, math-heavy college majors and highly quantitative occupations. We develop a general equilibrium model with multiple education outcomes, where wages are driven by individuals' ex ante abilities and acquired math skills. A large portion of within-group and general wage inequality is explained by math-biased technical change (MBTC).
\end{abstract}

JEL classification: E20, E24, E25, I20, I24, J24, J31

Keywords: wage inequality, SBTC, college majors, occupations, mathematics abilities

\footnotetext{
${ }^{*}$ We would like to thank seminar and conference participants at the University of Cergy-Pontoise, University of Zurich, SED Seoul, and NASM Los Angeles for valuable comments. Michelle Rendall gratefully acknowledges financial support from the European Research Council (ERC Advanced Grant IPCDP229883).

${ }^{\dagger}$ University of Zurich, Graduate School of Business, Plattenstrasse 14, CH-8032 Zurich. Email: andrew.rendall@uzh.ch.

${ }^{\ddagger}$ University of Zurich, Department of Economics, Schoenberggasse 1, CH-8001 Zurich. Corresponding Email: michelle.rendall@econ.uzh.ch. We are solely responsible for errors and omissions.
} 


\section{Introduction}

Math is a language of logic. It is a disciplined, organized way of thinking. There is a right answer; there are rules that must be followed. More than any other subject, math is rigor distilled. Mastering the language of logic helps to embed higher-order habits in kids' minds: the ability to reason, for example, to detect patterns and to make informed guesses. Those kinds of skills [have] rising value in a world in which information [is] cheap and messy. ${ }^{1}$

The US has seen a large rise in wage inequality since the mid-1970s (see Figure 1). While skill-biased technical change (SBTC) can match the average wage trend as measured by the college wage premium (i.e., college/non-college), the large and increasing within-group wage inequality is ignored. This paper documents the increasing importance of math skills in the labor market, where labor augmenting technical change biased toward math skills can account for a large part of the observed within-group inequality.

Determining which individuals are driving wage inequality and what makes them special yields three facts that support math as a driver of wage inequality:

1. Highly quantitative occupations have exhibited increasing relative wages since the mid-1970s.

2. Highly quantitative occupations and the math content of college majors are highly correlated.

3. Students attempt to study majors with the highest math content, but are constrained by their initial abilities. ${ }^{2}$

Two distinct trends emerge when measuring the importance of general ability and

\footnotetext{
${ }^{1}$ Amanda Ripley, The Smartest Kids in the World: And How They Got That Way

${ }^{2}$ Note, we use the terms "initial-" and "ex ante" ability interchangeably. Initial or ex ante ability refers to the ability an individual has upon completing high school.
} 


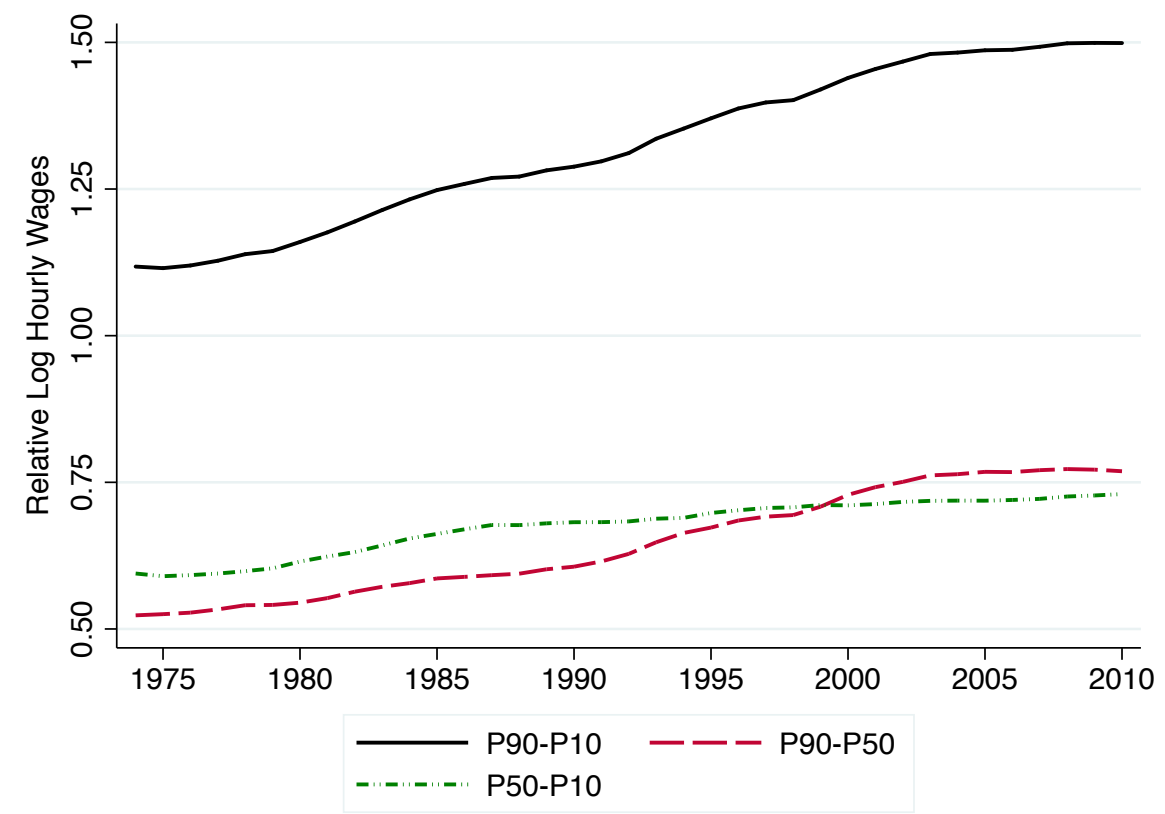

Source: IPUMS-CPS (see King et al., 2010). Log wages are residual wages from a regression of hourly log wages of full-time (at least 35 hours of work and 40 weeks per year) male workers aged 25 to 59 on age, age squared, dummies for education, race, state, and marital status.

Figure 1: US Wage Inequality

math skills. ${ }^{3}$ The increasing importance of math skills for college educated individuals is shown in panel (a) of Figure 2, where increasing wage returns to math skills are set against the stagnant returns of general ability. In contrast, the non-college group has experienced the opposite, with decreasing wage returns to math skills set against increasing returns to general ability. This evidence, combined with the three facts above, suggests that the US economy has not only experienced SBTC, but also math-biased technical change (MBTC), where MBTC cannot be exploited through college attendance alone. More precisely, students who study math-related topics in college will enjoy the largest wage benefits. Thus, the trends presented in Figure 2 emphasize MBTC as a mechanism

\footnotetext{
${ }^{3}$ General- and math ability are measured by the Armed Forces Qualification Test (AFQT) from the National Longitudinal Survey of Youth 1979 (NLSY79). General ability is a combination of math- and verbal abilities for the 1979 cohort (see, Altonji et al., 2012, for details on the construction of standardized AFQT scores).
} 


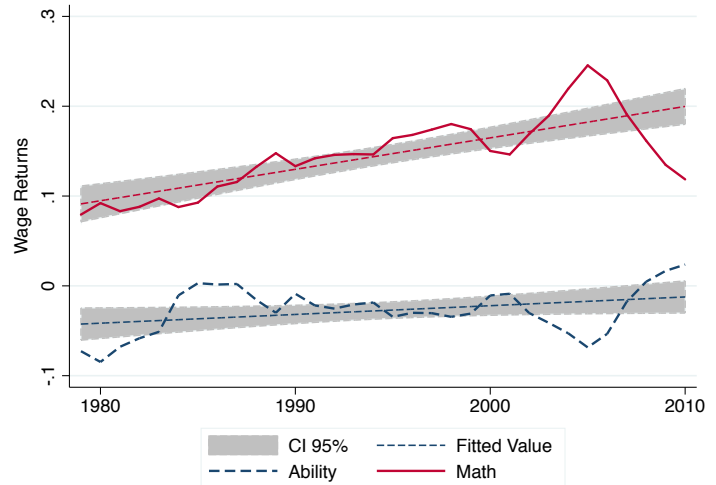

(a) College Graduates

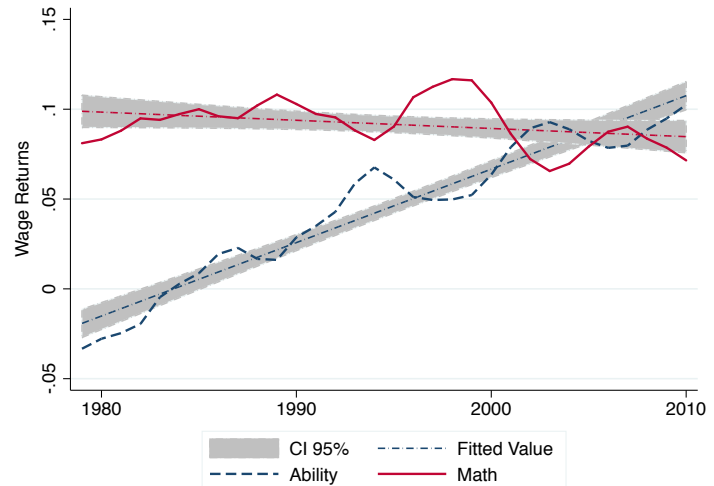

(b) Less than College

Source: NLSY79 (males aged 14-22 in 1979). Wage returns are computed from yearly regressions of hourly log wages of full-time workers (at least 35 hours in main job) on standardized AFQT test score, standardized AFQT math scores, age, age squared, dummies for race, region, marital status, and whether the individuals lives in a MSA or not.

Figure 2: Wage Returns

underpinning income inequality between college graduates. MBTC is unlikely to be the main driver of income inequality within the bottom half of the US wage distribution.

The facts and trends discussed above complement the research by Kambourov \& Manovskii (2009), who explain a large part of within-group wage inequality by focusing on occupational mobility and the cost of switching occupations. They find that occupational mobility accounts for a significant portion of wage inequality. Similarly, Huggett et al. (2011) study lifetime inequality by decomposing the contribution between initial human capital endowment and "luck," finding that 61.5 percent of the variation in lifetime earnings are due to initial endowments. However, the authors are silent on the decisions (forces) that lead to the differences in human capital at age 23. Thus, we expand on this body of research by modeling the initial conditions that proceed labor force choices. Our approach differs from Kambourov \& Manovskii (2009) and Huggett et al. (2011) by explaining what shapes the individual heterogeneity at the time of occupational choice (i.e., they do not model the formal college human capital accumulation process). We believe the formation 
of initial conditions (by age 23 when entering the labor market) to be important, as education choices matter for occupation decisions later in life. We show that intra-education group variance is missed when separating the population strictly by educational attainment (college, non-college) alone.

Intra-education group income inequality motivate Altonji et al. (2012), who find that male electrical engineers earn 51.6 percent more than male education majors, which is comparable to the college wage premium of 57.7 percent. However, due to the empirical focus of their research, they only estimate disaggregated cross-sectional returns to college majors with associated math and verbal SAT scores. The authors note that this area of research is relatively unexplored, but is important for understanding the structural mechanisms underpinning the ex post outcomes of higher education. A comprehensive review of the existing empirical studies on the returns to college major can be found in Table 2 of Altonji et al. (2012). Specifically, the authors note that there is lack of research explaining why individuals choose different education types, and how this translates into occupational choices. A crucial difference between our research and Altonji et al. (2012) is, by using the information on mathematic skill requirements within occupations from the Dictionary of Occupational Titles ${ }^{4}$ (DOT), we show that mathematics-focused majors are highly correlated with ex post wage outcomes through the occupational choices available to these majors. We hypothesize that wage inequality is driven, to a large extent, by individuals' initial abilities, which limit education options and, consequently, occupational choices.

Addressing similar wage discrepancies as Altonji et al. (2012), Silos \& Smith (2012) look at the trade-off between acquiring specific and targeted human capital. They concentrate on individuals' choices between education paths leading to specific occupations versus education paths that have broader applicability, and thus more occupational choice. The authors show that policies directed at occupation-specific human capital accumulation lead

\footnotetext{
${ }^{4}$ Dictionary of Occupational Titles, 1977 and 1991
} 
to lower income growth and lower inequality. MBTC sits within the broader educational transition described above. We emphasize the importance of the skill types accumulated, with particular attention given to mathematics as either a specific necessary ability or as a strong indicator of associated abilities. Those who have major in math-intensive areas may initially sort into high-wage occupations, with little incentive of switching (to alternative) occupations.

Carneiro et al. (2011) and Eisenhauer et al. (2013) explore another dimension of intraeducation group income inequality and find that the returns to college enrollment are approximately zero for low ability individuals, and possibly negative. MBTC is a potential mechanism that explains this observation, as math-light college majors, without exception, occupy the bottom of the college group wage distribution. Furthermore, there is a significant mass of college graduates with zero and three college math credits.

The idea of SBTC found in Acemoglu (2002), which builds upon the empirical work of Bartel \& Lichtenberg (1987) and Autor et al. (1998), formalizes a model in which the labor augmenting technical change is divided along the education dimension (college/noncollege). This model has become a workhorse for analyzing and explaining the persistent increase in the relative wages of college graduates. Our work builds on this existing framework by focusing on the distributional wage changes between college graduates. We add a separate mechanism that approximates the specific skills driving wage inequality intracollege graduates.

The college attendance mechanism in this paper is loosely based on Hendricks \& Schoellman (2014). In that paper the authors look at the discrete education choices of individuals (i.e., high school, some college, and college), focusing on ex ante abilities as measured by IQ scores. Their results show that one-third of the college wage premium and one-fourth of its growth is driven by ability ("ability premium"). While looking at ability as a driver of wage outcomes, Hendricks \& Schoellman (2014) define broad education categories that mask the sub-group mainly driving wage inequality: the top earning college graduates, 
who exhibit strong mathematical abilities.

This paper is unique in linking ability, acquired math skills, occupations and rising wage inequality. We aim to explain the evolution of the college graduate wage distribution using a model that emphasizes MBTC combined with the three facts previously discussed. The model revolves around the education choice. Individuals make a choice to attempt college or directly enter the labor market. As we are interested in the outcome of the college education process, we directly assign individuals math credits subject to ability constraints, with some individuals dropping out of college. Math credits characterize each college major in our model. Individuals supply both their ex post ability and any acquired math skills to the labor market. Only college graduates can supply the math skills associated with college majors. Firms hire college and non-college labor. Wage inequality is driven by both generic SBTC and specific MBTC.

Our results highlight the strength of MBTC as a determinant of intra-college graduate income inequality. With SBTC alone, the college wage premium is matched through all college graduate wages growing over time, which ignores the observed intra-group trends. In contrast, a combination of SBTC and MBTC matches both the aggregate and intragroup trends observed in the data: the stagnation of wages at the bottom of the college graduate group and the substantial increase in wages for the top college graduates.

Wage inequality across different education groups, mathematic requirements of college majors and quantitative occupation requirements form the basis of our model. Thus, Section 2 provides a summary of the data facts related to wage inequality, occupations and college majors over time and across cohorts. The general equilibrium model is outlined in Section 3, Section 4 explains the calibration procedure, and Section 5 provides analytical results. Section 6 concludes. 


\section{Data}

This research relies on three facts listed in the introduction and expanded upon in this section. Together, these three points present a coherent story of ex ante mathematical ability dictating college major options, from which occupations and, ultimately, wages are determined. Those with higher mathematics abilities pursue math-heavy majors and occupations. These particular occupations also enjoy the highest wages. Furthermore, the math intensive majors that lead to higher wage occupations are increasingly shunned by each subsequent generation of college degree holders. This shift away from math-heavy majors further exacerbates wage inequality.

\subsection{Who is Driving Wage Inequality?}

To illustrate which education-group subsets are driving wage inequality, we use data from the Current Population Survey (CPS), from which the residual of a Mincer wage regression is derived from log hourly wages of full-time, full-year males aged 25-59. The regression controls for age, age-squared, race, marital status, and state of residence (using CPS weights). The unexplained residual for various education-wage groups are compared in Figure 3. We use the notationally convenient abbreviations for wage percentiles: "C" for college, "NC" for non-college, and the "A" for the total population (all).

The cross-education wage-group comparisons highlight the importance of high-earning college graduates in driving wage inequality, especially since the mid-1980s. Figure 3a compares the residual wages of the $\mathrm{C} 10$ and $\mathrm{C} 20$ with the $\mathrm{NC} 80$ and $\mathrm{NC} 90$ wage groups, normalized against the A50 (50th percentile in the total sample). The bottom earning college graduates have significantly lower wages than the upper non-college wage groups and the average wage. All comparisons show a flat or mild divergence. The final comparison within Figure 3a shows the bottom college-wage decile has lost ground against the average individual. To put the average into perspective, college-graduates account for about 30 percent of the sample. That is, the average individual (A50) is a non-college graduate, just 


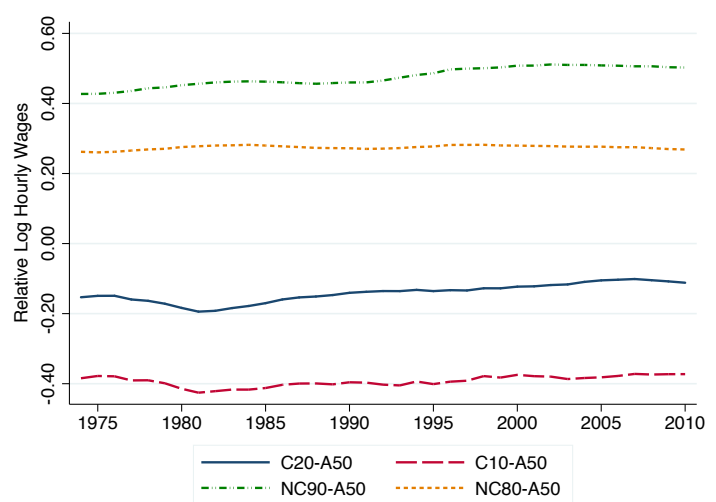

(a) Bottom

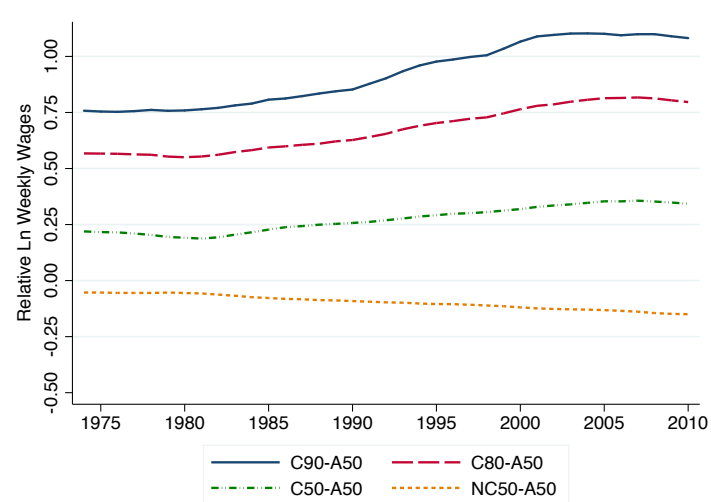

(b) Top

Source: CPS. See Figure 1 for the computation of log hourly wages.

Figure 3: Wage Performance

above the average non-college (NC50) individual (see Figure 3b bottom line).

In contrast to Figure 3a, Figure 3b compares the residual wages of the middle and top college, and the middle non-college wage groups with the average individual. The C90 wage group has outpaced the C50 wage group by 20 percent since the mid-1970s. This is a remarkable performance considering the C50 wage group increased their wage premium against the median individual by approximately 12 percent. For reference, the college wage premium grew by 22 percent. The implications of this figure are summarized in two points: (1) the average college graduate is outpacing all other groups, but (2) the top college graduates are sprinting ahead of everyone. Thus, a large part of wage inequality growth is driven by the top college-wage groups, while the bottom college-graduates are left behind compared to a large share of non-college graduates.

\subsection{Fact 1: MBTC}

As within-group wage inequality is driven by the top earners, it is important to pin down the characteristics that defines this group. The idea of MBTC is compelling when considering the relative returns to math and general ability previously presented in Figure 2 for the National Longitudinal Survey of Youth 1979 (NLSY79) cohort. For college grad- 


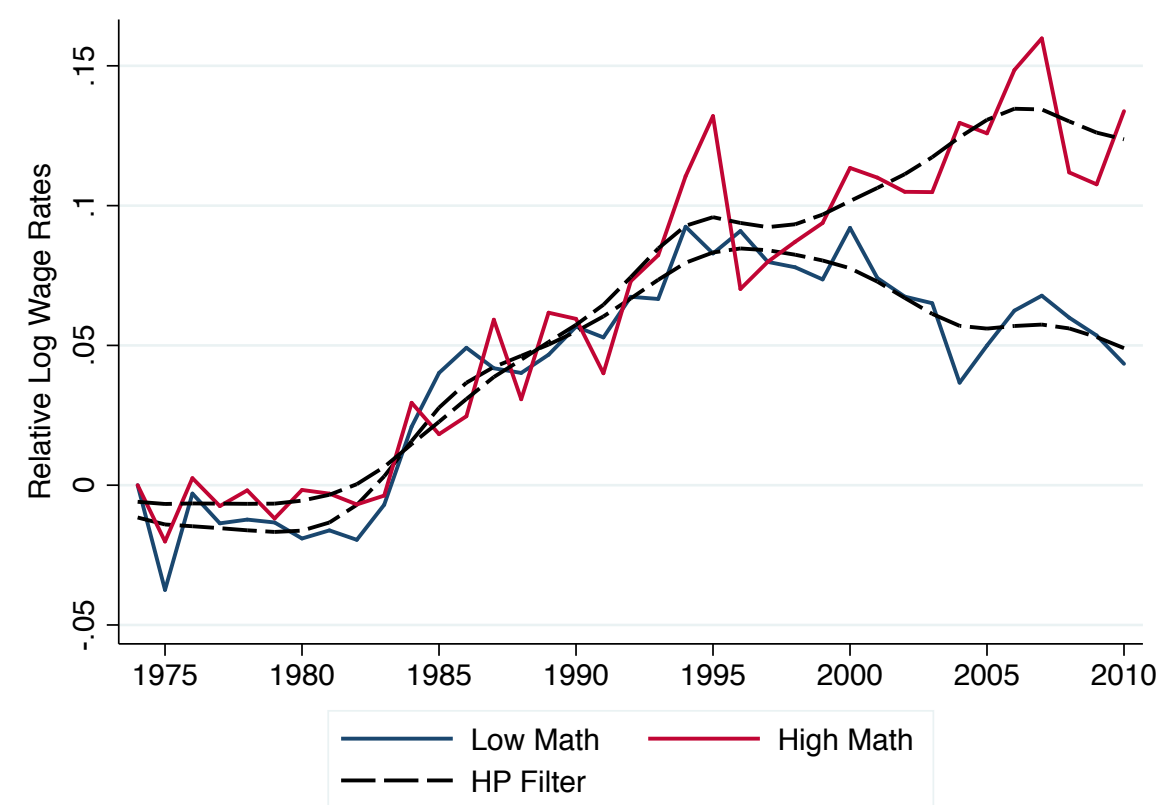

Source: CPS. See Appendix B on the detailed computation of log wage rates.

Figure 4: Relative Log Hourly Wages of High- to Low-Math Occupations

uates, labor market returns to math have increased over time, with the evidence pointing to MBTC as the driver. However, estimating MBTC together with SBTC requires a time series dataset of the US economy. As the American Community Survey (ACS) only has cross sections for 2009 and 2010, we use the DOT numerical requirements to exploit the time series dimension of the CPS to further understand the importance of MBTC. ${ }^{5}$ Figure 4 shows relative log wage rates of college graduates split equally between high- and lowmath occupations ${ }^{6}$ relative to non-college wage rates. The wage rates are computed using efficiency units of labor, with more detail on the precise computation found in appendix B. The relative wages of high-math occupations began to diverge in the mid-1980s, which is consistent with the beginning of large-scale personal computer adoption, a main driver of SBTC (Autor et al., 1998). Results suggest that, for college graduates, labor augmenting

\footnotetext{
${ }^{5}$ Appendix A provides additional detail about the DOT aptitude measures used in this paper.

${ }^{6}$ The $50 \%$ split means that the cutoff between low- and high-math occupations is such that $50 \%$ of college graduates in 1974 work in high-math occupations. However, the results are not sensitive to this cutoff, e.g., using a top-third versus bottom two-thirds split yields similar quantitative results.
} 


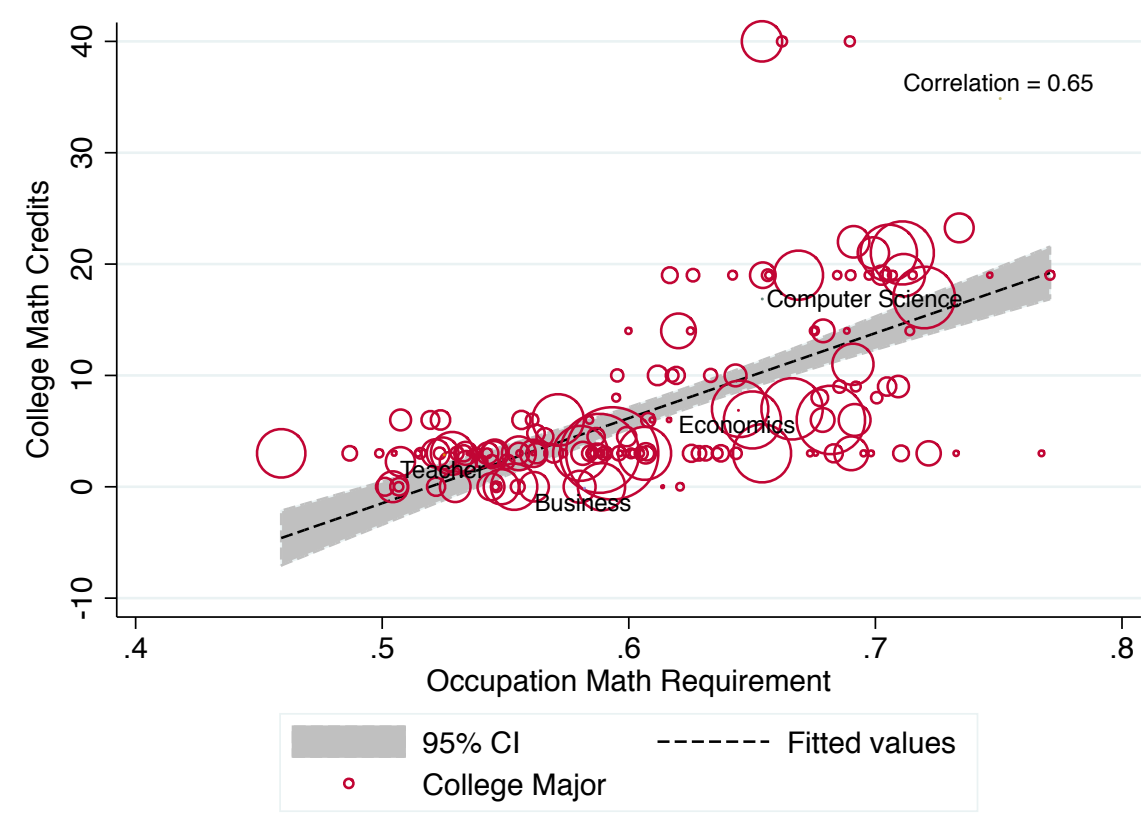

Source: ACS, NCES, DOT. Full-time, full-year, males, age 23-62.

Figure 5: Occupation Math Requirements and College-Level Math Credits by Major

technical change on high-math occupations has grown about 16 percent per annum faster than on low-math occupations. Appendix B provides details on the estimation method for both SBTC and MBTC over time using the CPS.

\subsection{Fact 2: College and Work}

Figure 5 depicts the relationship between college majors' math credits and the numerical skill requirements of occupations in 2010 for individuals aged 23 and 62 . The figure uses the individual-level observations with college major and occupation information from the ACS, combined with the DOT numerical job requirements. ${ }^{7}$ All individuals are first grouped by their college major and the average occupation math requirement is computed, as there are multiple occupation outcomes within each college major. This figure shows that occupation-specific math skills are highly correlated with college-level math credits

\footnotetext{
${ }^{7}$ The ACS 2010 is used throughout. The ACS 2009 is the first year in which college major is included. Note that the trends observed in the ACS 2010 are virtually identical to the ACS 2009.
} 


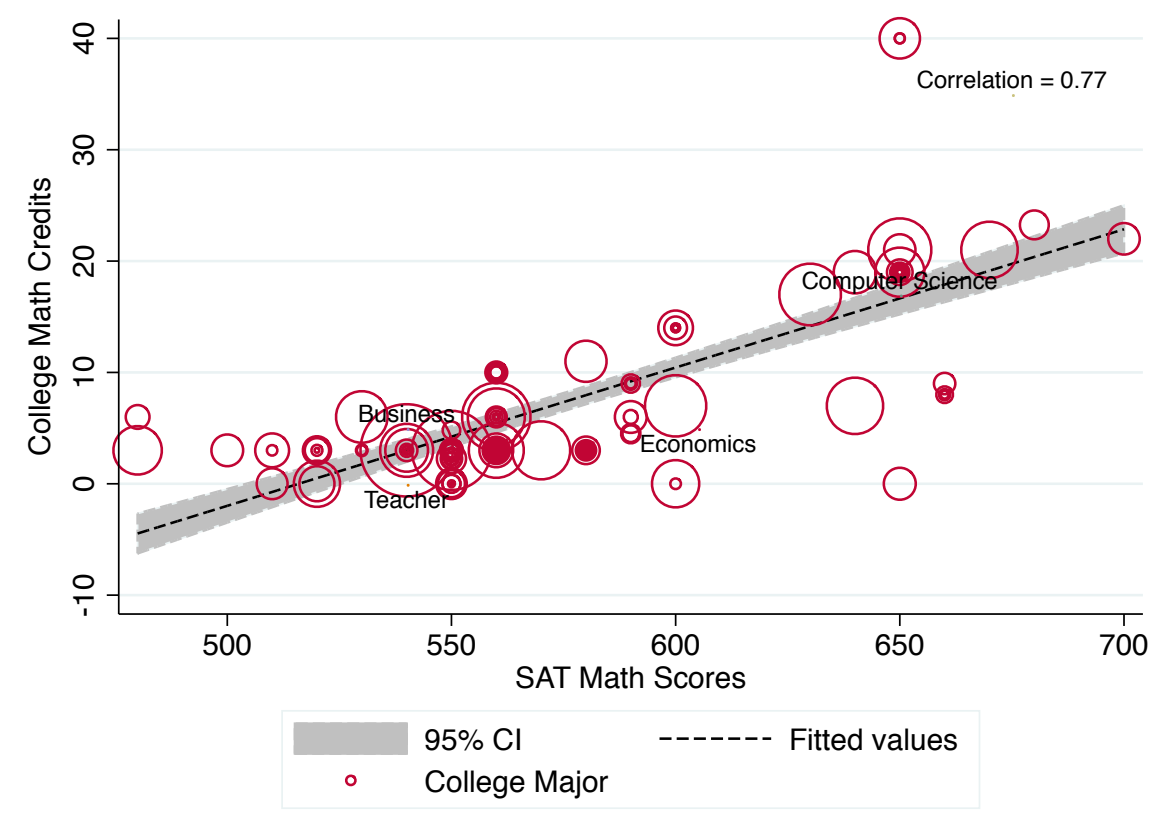

Source: ACS, NCES. Full-time, full-year, males, age 23-62.

Figure 6: SAT Math Scores and College-Level Math Credits by Major

by college major, with a 0.65 correlation coefficient.

\subsection{Fact 3: College Math and Ability}

Looking at the initial characteristics that lead to college major sorting, Figure 6 merges college-level math credits and mean SAT Math scores by college major from the National Center for Education Statistics (NCES) to individuals in the ACS. The results illustrate that ex ante abilities are correlated with college-level math credits with a correlation coefficient of 0.77 . Thus, those with high-math abilities prior to college, as measured by the average SAT Math scores of those graduating within a specific college major, are more likely to graduate from math intensive college majors, as measured by college-level math credits. 


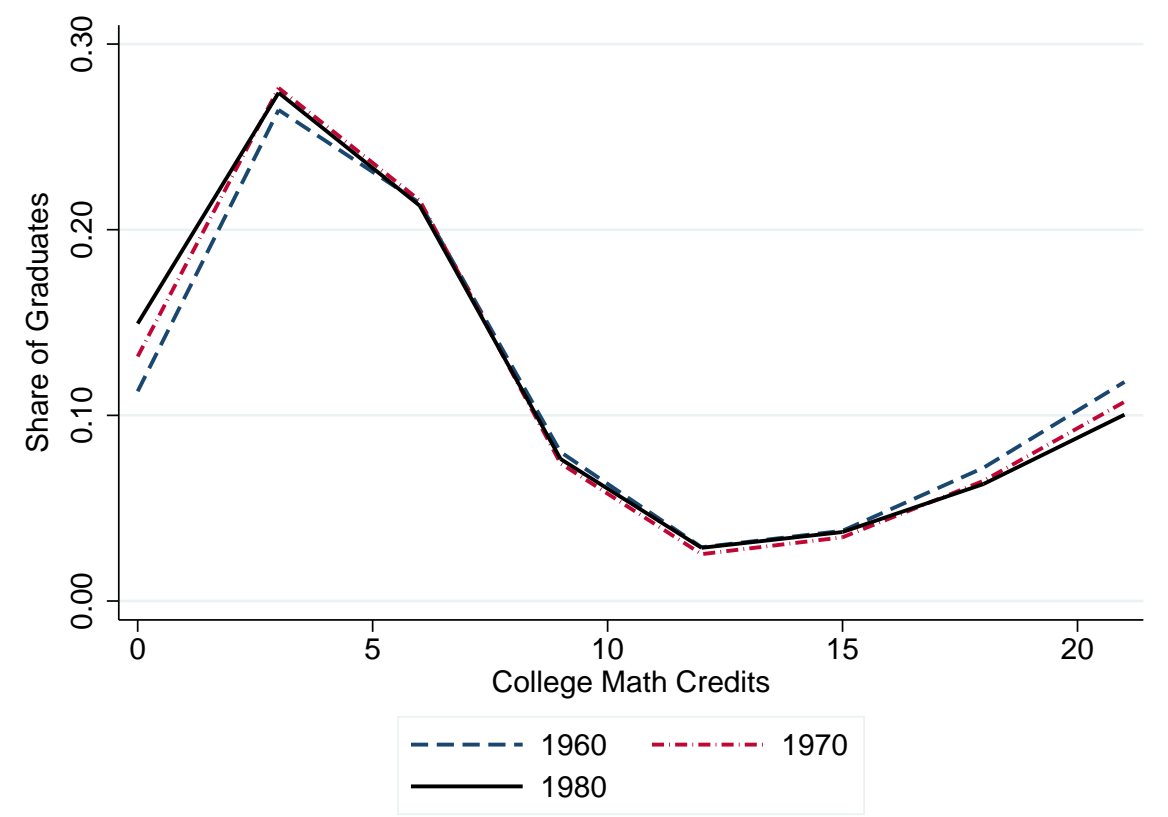

Source: ACS, NCES. College graduate males by birth cohort.

Figure 7: College Major Graduation Share by Cohorts

\subsection{Other Measures}

The ACS offers a cross-sectional snapshot of college majors in 2010, from which we construct a measure of how individuals' college major choice has evolved. This assumes that most individuals do not go back to school beyond the age of 30, and that the ACS sample is representative of the population at every age group. Figure 7 illustrates the changes in degrees obtained, as measured by the share of graduates at each math credit level of three sample cohorts between the 1960s and 1980s. The figure shows a general and persistent pattern of college graduates shifting away from relative high-math majors to low-math majors since the 1960s. Given the general trend toward MBTC in the labor market, this pattern may seem puzzling. However, the leftward shift in the quality of college students, suggested by Hendricks \& Schoellman (2014) and Heckman \& Mosso (2014), can also explain a shift towards the left in Figure 7. The hypothesis to be tested in this paper is to precisely determine the importance of MBTC combined with this shift 
Table 1: Ability Measures and Wages

\begin{tabular}{lccccc} 
& $\log (\mathrm{w})$ & AbilityG & AbilityV & AbilityN & SATM \\
\hline AbilityG & $0.601^{* * *}$ & 1 & & & \\
AbilityV & $0.563^{* * *}$ & $0.966^{* * *}$ & 1 & & \\
AbilityN & $0.846^{* * *}$ & $0.766^{* * *}$ & $0.719^{* * *}$ & 1 & \\
SATM & $0.609^{* * *}$ & $0.598^{* * *}$ & $0.571^{* * *}$ & $0.725^{* * *}$ & 1 \\
SATV & $0.387^{* * *}$ & $0.565^{* * *}$ & $0.551^{* * *}$ & $0.502^{* * *}$ & $0.796^{* * *}$ \\
\hline${ }^{*} p<0.05,{ }^{* *} p<0.01,{ }^{* * *} p<0.001$ & & &
\end{tabular}

towards low-math majors in generating the observed increase in wage inequality within college graduates.

Table 1 shows how other measures of ability are correlated with log wages, college math credits and the usual SAT measures of ex ante math and verbal ability. AbilityG, AbilityV and AbilityN are the DOT measures for general, verbal and numerical aptitudes, respectively. ${ }^{8}$ The results presented here are for all individuals, with similar results across cohorts. However, the correlation between log wages, general- and verbal ability are smaller for younger cohorts. For example, individuals aged 28 to 32 in 2010 (the 1980 cohort) have a correlation between wages and general ability of 0.46 , verbal ability of 0.43 and math ability of 0.78 . The population correlations for these same measures is $0.60,0.56$, and 0.85, respectively (see Table 1). This difference may be due to an age-effect when first entering the labor market, i.e., individuals learn about different occupations and their skill requirements through experience.

The correlation for math measures (SATM, AbilityN) are 40-60 percent greater than non-math measures. While this is possibly due to noise within the non-math measures, the correlation between SATM and SATV is 0.80. This high correlation between math and verbal scores, despite the much higher correlation between log wages and math scores, further highlights the special significance of math as either a direct or indirect measure of high-return skills in the labor market. Note that, with respect to the timing of collegelevel education, the DOT ability measures are ex post assessments, whereas the SAT ability

\footnotetext{
${ }^{8}$ The DOT measures of ability are detailed in Appendix A.
} 


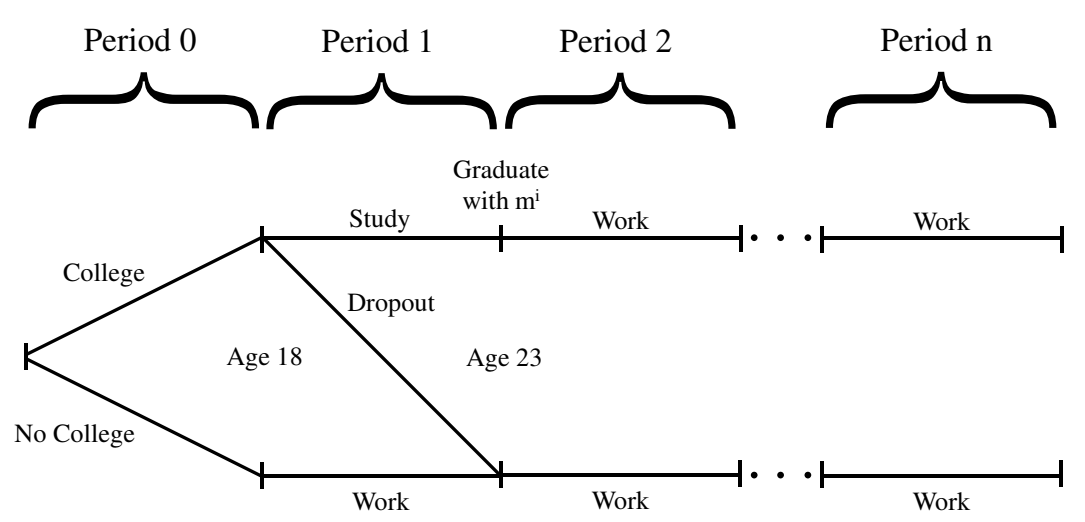

Figure 8: Timeline for Individuals

measures are ex ante assessments.

\section{Model}

As this research is focused on the evolution of wage inequality over time, a general equilibrium model is required to provide the time dynamics that would invariably be ignored by estimating a regression model on the cross sections of available data. The overlapping generations model used here features a unit mass of finitely lived agents and a single representative firm.

\subsection{Individuals}

The model is loosely based on Hendricks \& Schoellman (2014). However, the schooling decision is modified to incorporate a choice between "college majors" and the fact that individuals face constraints based on their ability. Figure 8 provides the basic model timeline for individuals. For each generation, there are two primary periods with all decisions taking place in period 0 and the realization of the decisions occurring in period 1 . During period 0 , individuals choose to either enter or forgo college (college or non-college). At the beginning of period 1 , individuals are about 18 years old. If they attempt college there 
are two outcomes: (1) drop out/fail or (2) graduate with a specific degree characterized by specific acquired math skills, $m^{i}$. Both college graduates and dropouts enter the labor force in period 2, with individuals who drop out/fail losing one period of income as an opportunity cost of attempting college. Each subsequent period, individuals supply their general ability and acquired math skills to firms in exchange for wages.

Individuals' decisions within the model are straightforward. Individuals decide to pursue college education or enter the labor market in period 0 . This is the only choice available to individuals in this model. Dropping out is determined by a single ability cutoff. The college major "choice" is simplified to a direct mapping from human capital, $h_{m}$, to acquired math skills, $m$, without an explicit choice. Arcidiacono et al. (2012) and Zafar (2013) find strong evidence that men optimize their education choices in order to earn the highest wage return. Also exploring men's education choices, Paglin \& Rufolo (1990) find empirical evidence that men choose college majors based on their math ability. This result is similar to that of Stinebrickner \& Stinebrickner (2014), who show that many people attempt math-heavy college majors, but learn about their abilities through failure. These people move into college majors with lighter math loads, with the failure and "drop" process repeating until the student's ability is matched to the math content of the college major or they drop out. Thus, for men, combining these results points to a direct mapping from initial ability to the highest possible college math outcome.

The education choice is determined by weighing the financial benefits against the utility and opportunity costs (lost wages) of studying. Markets are complete, such that income maximization and consumption maximization yield the same results, with discounting of $\beta=\frac{1}{1+r}$. Thus, the individuals' objective function is:

$$
\max _{s^{i}}\left\{\sum_{t=2}^{N}\left(\frac{1}{1+r}\right)^{t} E\left[p(\theta) \omega_{e t}\left(\theta, \theta_{m}\right)+(1-p(\theta)) \omega_{u t}(\theta)\right]-\zeta^{i}, \sum_{t=1}^{N}\left(\frac{1}{1+r}\right)^{t} E\left(\omega_{u t}(\theta)\right)\right\} .
$$


Individuals make a schooling choice, $s^{i} \in\{e, u\}$, between attending college or not. Individual wages are given by $\omega_{j t}^{i}$, with $j=\{e, u\}$ denoting the college graduate (educated) or non-college (uneducated) outcomes. Wages are a function of individuals' initial general ability, $\theta^{i}$. College-graduate wages are, in addition, also a function of individuals' initial math ability, $\theta_{m}^{i}$. The probability of graduating from college is represented by $p$ and depends on an individuals' initial general ability, $\theta^{i}$. Individuals are heterogeneous across initial general ability $\left(\theta^{i}\right)$, initial math ability $\left(\theta_{m}^{i}\right)$ and taste for college $\left(\zeta^{i}\right)$.

While initial ability is defined in terms of $\theta^{i}$ and $\theta_{m}^{i}$, agents are aware that ability translates into human capital $\left(h^{i}\right)$, through a noisy process, that affects their performance both at school and at work. This process is defined as $h^{i}=\exp \left(\theta^{i}+\epsilon^{i}\right)$ and $h_{m}^{i}=\exp \left(\theta_{m}^{i}+\right.$ $\left.\epsilon^{i}\right)$ for general and math human capital, respectively. Individuals' ex ante estimate of their general and math human capital is given by $\hat{h}$ and $\hat{h}_{m}$. Students generally overestimate their human capital when making schooling choices, which we call overconfidence (for an empirical motivation see Bordalo et al., 2014, and references therein). This overconfidence is seen in individuals' ex ante general and math human capital estimates: $\hat{h}=\exp (\theta+\hat{\epsilon})$ and $\hat{h}_{m}=\exp \left(\theta_{m}+\hat{\epsilon}\right)$, where $E(\hat{\epsilon})>E(\epsilon)$.

College is not reversible and dropping out occurs only if an individual does not meet the minimum graduation requirement set by $\bar{h}$. I.e., $p\left(\theta^{i}\right)=1$ if $h^{i}(\theta)>\bar{h}$ otherwise $p=0$ and the individual drops out of college.

Math human capital has no value in the labor market unless an individual studies math in college. We will approximate this college major matching process by allocating math credits directly to individuals based on their ability. Acquired math skill in college, $m^{i}\left(h_{m}\right)$, is an increasing function of math human capital, $\frac{\partial m^{i}\left(h_{m}\right)}{\partial h_{m}}>0$.

The wages for college educated individuals are determined by,

$$
\omega_{e t}^{i}=w_{e t}\left(w_{h e t} h^{i}+w_{m e t} m^{i}\left(h_{m}\right)\right) \exp \left(\eta_{t}^{i}\right)
$$


where $w_{e t}$ are general wage returns to a college degree for general human capital (indexed $h$ ) and acquired math skill (indexed $m$ ). A transitory luck component, $\eta$, is drawn each period.

The wages for uneducated individuals are,

$$
\omega_{u t}^{i}=w_{h u t} h^{i} \exp \left(\eta_{t}^{i}\right)
$$

as math human capital has no value unless refined in college. Uneducated individuals face the same transitory luck component, $\eta$, as educated individuals.

\section{$3.2 \quad$ Firms}

A representative firm hires college and non-college labor to produce a final good $\left(Y_{t}\right)$. The production function is a CES between non-college and college labor. College labor is a nested-CES between general human capital and math. Non-college labor, by definition, only supplies general human capital.

$$
Y_{t}=\left[\alpha L_{h u t}^{\nu}+(1-\alpha)\left[\lambda\left(A_{t} L_{h e t}\right)^{\rho}+(1-\lambda)\left(A_{t} M_{t} L_{m e t}\right)^{\rho}\right]^{\nu / \rho}\right]^{1 / \nu}
$$

The elasticity of substitution between education types is $\frac{1}{1-\nu}$. The elasticity of substitution between general human capital and acquired math skills is $\frac{1}{1-\rho}$. Labor shares are comprised of two components for educated individuals, general human capital and acquired math skills, and general human capital alone for uneducated individuals. Formally, labor shares are defined as,

$$
L_{h j t}=\int_{i}\left(\mathbf{1}_{\left(s^{i}=j\right)} h^{i}\right) d i, \forall j=e, u \quad \text { and } \quad L_{m e t}=\int_{i}\left(\mathbf{1}_{\left(s^{i}=e\right)} m^{i}\right) d i .
$$

$A_{t}$ is skill-biased technical change (SBTC) and $M_{t}$ is math-biased technical change (MBTC) over time, with growth rates $\gamma_{a t}$ and $\gamma_{m t}$ for SBTC and MBTC, respectively. 
Thus, SBTC is $A_{t}=\left(1+\gamma_{a t}\right) A_{t-1}$ and MBTC is $M_{t}=\left(1+\gamma_{m t}\right) M_{t-1}$.

The model solutions follow from the firm's cost minimization problem. If we define college labor output as,

$$
Y_{e t}=\left[\lambda\left(L_{\text {het }}\right)^{\rho}+(1-\lambda)\left(M_{t} L_{\text {met }}\right)^{\rho}\right]^{1 / \rho},
$$

with a price of $p_{e t}=w_{e t}$, given perfect competition, then the relative demand for college labor output from the firm's minimization is,

$$
\left(\frac{Y_{e t}}{L_{h u t}}\right)_{\text {demand }}=\left(\frac{A_{t}^{\nu}(1-\alpha)}{\alpha} \frac{w_{h u t}}{w_{e t}}\right)^{\frac{1}{1-\nu}} .
$$

Firms demand relatively more college labor when the wage rate decreases or college labor productivity $\left(A_{t}\right)$ increases. The relative demand for acquired math skills ("college math") from the firm's solution is,

$$
\left(\frac{L_{\text {met }}}{L_{\text {het }}}\right)_{\text {demand }}=\left(\frac{M_{t}^{\rho}(1-\lambda)}{\lambda} \frac{w_{\text {het }}}{w_{\text {met }}}\right)^{\frac{1}{1-\rho}} .
$$

Firms demand relatively more college math when the wage rate decreases or the productivity of acquired math skills $\left(M_{t}\right)$ increases.

\subsection{Equilibrium}

The general equilibrium conditions are dependent on the individuals' and the firm's optimization problems.

An equilibrium, given wage rates $\left\{w_{h u t}, w_{e t}, w_{h e t}, w_{m e t}\right\}$, is defined by:

1. The education choice, $s^{i}=\{e, u\}$, that maximizes the individual problem, subject to the graduation constraint $h^{i} \geq \bar{h}$

2. The demand for labor $\left\{L_{h u t}, L_{h e t}, L_{m e t}\right\}$, that minimizes the firm's production cost; and 
3. Labor markets clear, both for general human capital, $\left(L_{h j t}\right)_{\text {demand }}=\left(L_{h j t}\right)_{\text {supply }}$ for $j=\{e, u\}$, and for college math, $\left(L_{\text {met }}\right)_{\text {demand }}=\left(L_{\text {met }}\right)_{\text {supply }}$.

\subsection{Dynamics}

To compute actual wage rates, the final good price is normalized to one, $p_{t}=1$. Using the unit cost of producing one unit of output, it is straight forward to derive all wages from Equations (4)-(6). The wage rates of college labor input are,

$$
w_{h e t}=w_{e t} \lambda^{1 / \rho}\left(1+\frac{M_{t}^{\rho}(1-\lambda)}{\lambda}\left(\frac{L_{m e t}}{L_{h e t}}\right)^{\rho}\right)^{(1-\rho) / \rho}
$$

and

$$
w_{m e t}=w_{h e t} \frac{M_{t}^{\rho}(1-\lambda)}{\lambda}\left(\frac{L_{h e t}}{L_{m e t}}\right)^{1-\rho}
$$

where

$$
w_{e t}=A_{t}(1-\alpha)^{1 / \nu}\left(1+\frac{\alpha}{A_{t}^{\nu}(1-\alpha)}\left(\frac{L_{h u t}}{Y_{e t}}\right)^{\nu}\right)^{(1-\nu) / \nu} .
$$

SBTC $\left(A_{t}\right)$ increases the returns to all college labor. There are two channels that increase the returns to math college, (1) a direct technical change effect, and (2) an indirect supply effect. First, MBTC $\left(M_{t}\right)$ increases the returns to college math directly. Second, a relatively faster increase in general human capital compared to the supply of college math, $\frac{L_{h e t}}{L_{m e t}}$, given an elasticity parameter of $\nu<1$, also increases the wage rate on college math, $w_{m e t}$. Therefore, consistent with our main hypothesis, if individuals are constrained in learning math, or new college entrants are unable to learn/study math, it is possible that the returns to math increase faster than the returns to college, leading to a larger spread between the top and bottom percentile wages within the college educated group. As a consequence, the larger the absolute number of college entrants, given that every new marginal entrant will have a lower ability level, the larger the post-education wage inequality. For completeness 
the wage rate of uneducated workers is determined by,

$$
w_{\text {hut }}=w_{e t} \frac{\alpha}{A_{t}^{\nu}(1-\alpha)}\left(\frac{Y_{\text {et }}}{L_{h u t}}\right)^{1-\nu}
$$

where the non-college relative wage decreases with SBTC, which is consistent with the SBTC literature.

\section{Calibration}

The model parameters can be grouped into four categories: (1) standard parameter values, $\{\beta, N\}$; (2) individual-specific parameters, $\left\{\mu_{\theta}, \sigma_{\theta}, \sigma_{\zeta}, \hat{\mu}_{\epsilon}, \sigma_{\epsilon}, \sigma_{\eta}\right\}$; (3) college-specific parameters, $\left\{\delta_{0}, \delta_{1}, \bar{h}, \bar{m}\right\}$; and (4) firm-specific parameters $\left\{\gamma_{j t}, \alpha, \lambda, \nu, \rho\right\}$. Each category of parameters is discussed in separate subsections below. The calibration procedure estimates all parameter values jointly.

\subsection{General Parameters}

The model has five-year time periods and is simulated for seven periods, from 1980 to 2010. We start the model economy at 1980 for two reasons: (1) the 1960 cohort of the NLSY79 is the first reasonable target available, i.e., individuals making their college decisions in 1980; and (2) the Vietnam War distorted the college decision of cohorts born before 1960, as the draft could be avoided by college enrollment (see Lemieux \& Card, 2001). In addition, the decompositions in Section 2 show that income divergence began around 1980, with a relatively flat trend between 1975 and 1980. The model uses a standard discount factor of $\beta=0.9$ per period, which implies a discount rate of approximately two percent per year.

We set $N=9$, meaning that individuals live for nine periods after the college/no-college decision. Thus, each period contains nine generations and the modeled working life-time of an individual covers the equivalent of 45 -years. As the period 0 decision is assumed to 
take place around the age of 18 , the model covers the age range of 18 to 63 . The simulation accounts for the baby boom/bust that generates different cohort sizes. However, the results are not sensitive to these cohort size differences.

\subsection{Individual and Education Specific Parameters}

The individual and education parameters interact directly. Therefore, this subsection discusses these two parameter groups together. Given that the NLSY79 was administered to individuals aged 14 to 22 in 1979, and model simulations start in 1980, we drop the youngest individuals for NLSY targets described below. That is, we match the 1960 cohort definition, only including individuals born before 1963.

Initial ability and human capital. The two types of initial ability, general $(\theta)$ and math $\left(\theta_{m}\right)$, are distributed normally. Formally, $\theta \sim N\left(0, \sigma_{\theta}^{2}\right)$ and $\theta_{m} \sim N\left(0, \sigma_{\theta}^{2}\right)$. The correlation $(\rho)$ between initial general ability and initial math ability is set to $\phi=0.9367$, matching the correlation between SAT I and SAT I Math scores in the ACS, $E\left(\theta_{m}\right)=\phi \theta$.

To generate the mapping between initial ability measures $\left(\theta\right.$ and $\left.\theta_{m}\right)$ and human capital ( $h$ and $h_{m}$ ), the noisy process $\epsilon$ is assumed $N\left(0, \sigma_{\epsilon}^{2}\right)$. The ex ante process $\hat{\epsilon}$ is also assumed $N\left(\hat{\mu}_{\epsilon}, \sigma_{\epsilon}^{2}\right)$.

Schooling choice. Preferences for studying impact the initial college/no college schooling choice. Study preferences are defined by $\zeta$, which can be considered an individual's taste for college. While individuals sort into college based on their initial ability, Figure 9 shows that this sorting is not perfect. Thus, $\zeta \sim N\left(0, \sigma_{\zeta}^{2}\right)$, where a negative $\zeta$ is a cost and a positive $\zeta$ is "love" for studying.

Schooling outcome. There are two outcomes for those who attempt college education: (1) dropout/failure or (2) graduate in a college major characterized by math credits. In the model, the dropout rate is governed by a minimum human capital standard, $\bar{h}$, which 


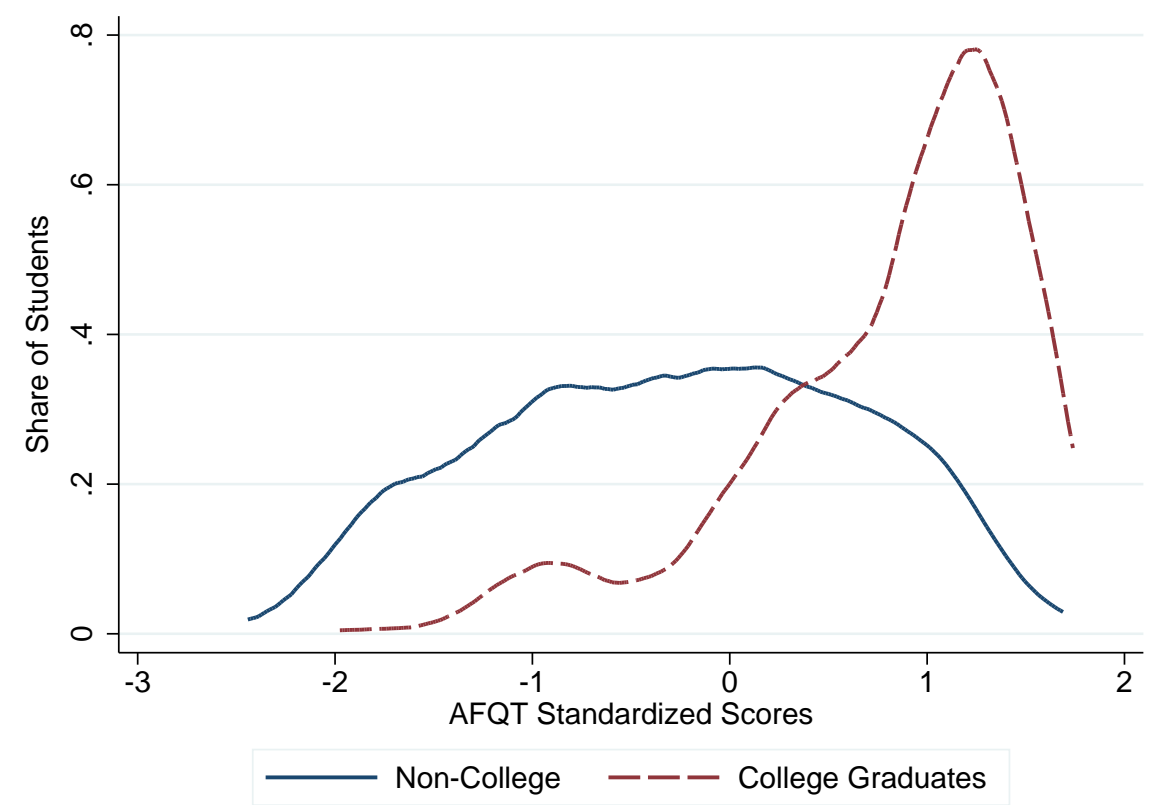

Source: NLSY79. Males born before 1963 (1960 cohort). Standardized test scores as computed by the method of Altonji et al. (2012).

Figure 9: Ability Distribution by Education Type

is assumed constant over time. Those who do not drop out of college accumulate a representative measure of acquired math skill in college $\left(m^{i}\right)$, with functional form,

$$
m^{i}=\min \left\{\bar{m}, \max \left(0, \delta_{0}+\delta_{1} \exp \left(h_{m}\right)\right)\right\}
$$

Math acquired in college is subject to a cap, $\bar{m}$, which is set to match the share of individuals with 21 or more math credits in the 1960 cohort. The choice of 21 math credits is driven by returns to math credits in the ACS sample. A regression of math credits and math credits squared on wages, controlling for a number of characteristics, for full-time full-year male employees, suggests an increasing and concave relationship for the returns up-to 21 college math credits (see Figure 10). The returns to additional credits above 21 flattens and then drops sharply at 40 credits. These 40 -credit college majors are primarily 


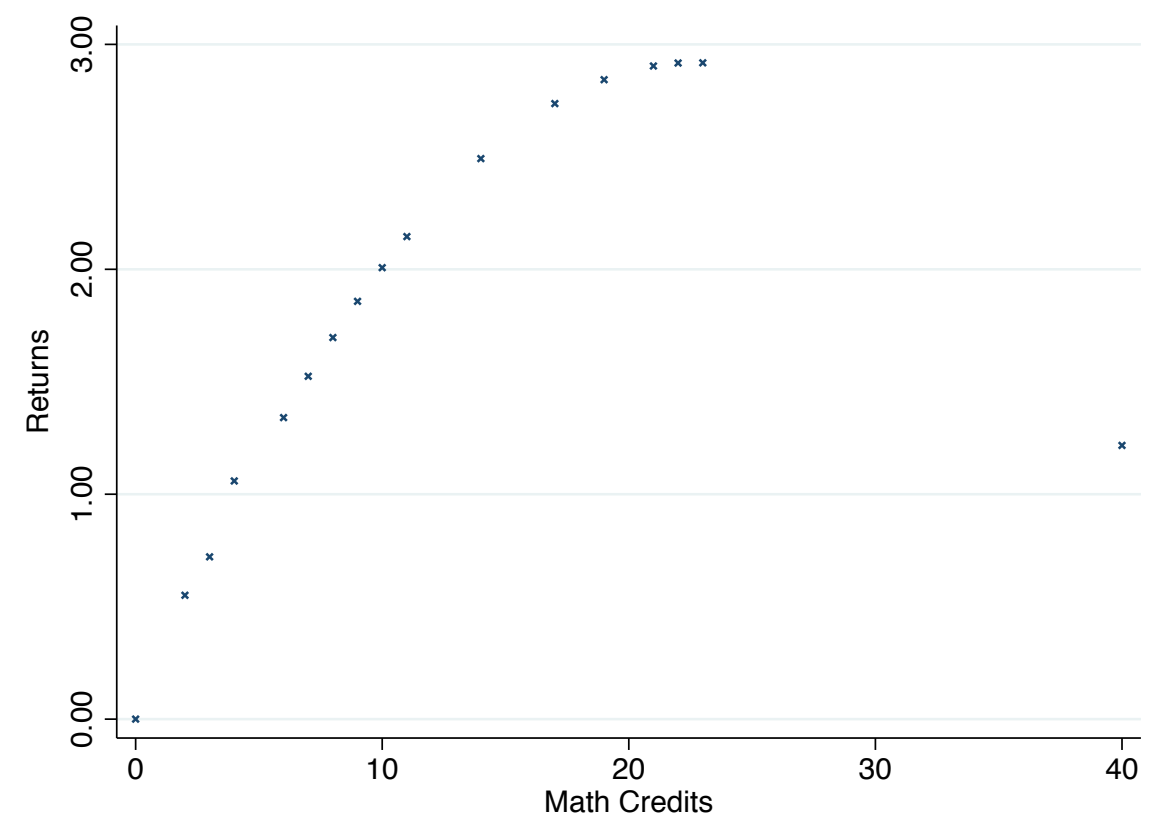

Source: ACS, NCES. Math credit returns are computed from a regression of hourly log wages of full-time (at least 35 hours of work and 40 weeks per year) male workers aged 25 to 59 on math credits, math credits squared, age, age squared, dummies for education, race, marital status, and year.

Figure 10: ACS Returns to College Math Credits

math majors. We argue that numerical skills and the tools learned in mathematics are valuable on the job market, but we do not, per se, think that esoteric math courses (e.g., chaos and dynamical systems) are the main driving force. However, the US share of college graduates with 40 credits is small. ${ }^{9}$

The number of college graduates studying zero math credits can be seen in Figure 7 . These individuals will benefit from SBTC, but not from MBTC. We define $\delta_{0}$ such that the share of college graduates from the 1960 cohort with zero math credits is matched. Given the mapping function for $m^{i}, \delta_{0}$ will be a negative value.

\footnotetext{
${ }^{9}$ Only 1.6 percent of college graduates within the entire 2009/2010 sample obtain 40 math credits.
} 
Additional wage component. The model features a standard luck component (e.g., Storesletten et al., 2001) in wages over the life-cycle. For the precise process used in this paper, see Guvenen \& Kuruscu (2010). This luck component is i.i.d. with mean zero and standard deviation $\sigma_{\eta}$.

Remaining moment conditions. The six structural parameters that do not have a oneto-one mapping to empirical moments are estimated by matching seven US data targets simultaneously. The seven moments that govern individual actions pertain to the 1960 cohort (i.e., individuals making education choices in 1980) or the year 1980. We group the moments that we believe to be particularly informative of a given parameters.

- $\bar{h}$ is governed by the college dropout rate in 1980. Although there is a wide range of estimates for the dropout rate, we use estimates by Bound et al. (2010) for two reasons: (1) the authors provide estimates disaggregated by gender; and (2) their definition aligns with our interpretation of college dropouts. That is, the college dropout rate defined as the share of all individuals age 25 in 1980, who have some college but lack a four-year college degree. More importantly for our research, the results presented below are not sensitive to the precise value of the dropout rate. Note that the model generates an increasing college dropout rate over time, which is a characteristic that the literature agrees on (for example, Bound et al., 2010; Bailey \& Dynarski, 2011, both show a rise in college dropout rates).

- $\hat{\mu}_{\epsilon}, \sigma_{\epsilon}, \sigma_{\zeta}$ are determined by the average general ability of college graduates (NLSY79, Armed Forces Qualification Test (AFQT)), the correlation of high school GPA and freshman college GPA of 0.4 (Rothstein, 2004), and the average ability of non-college workers (NLSY79, AFQT). That is, $\bar{h}$ provides a clear dropout cutoff, with overconfidence, $\hat{\mu}_{\epsilon}$, contributing to the dropout rate, i.e., people attempt college who cannot graduate. Uncertainty over actual abilities is generated by $\sigma_{\epsilon}$, with a large literature suggesting that SAT scores and high school performance are an imperfect 
measure of college performance, and significant information about own ability being revealed through studying at a college level. ${ }^{10}$ Lastly, $\sigma_{\zeta}$ generates imperfect sorting, since individuals have idiosyncratic preferences for school, which translates into a larger variance in the ability of college graduates. This variance is used to explain differences in the average ability between college and non-college individuals.

- $\sigma_{\theta}$ and $\delta_{1}$ are determined through three 1980 relative log wage targets: NC90-NC10, C90-C50, and C90-C10. These second moments cover the main intra-group inequality measures that we believe are important. Note that the model has an extra wage target. This additional second moment will provide information on the relevant parameters determining variance: $\sigma_{\theta}, \sigma_{\epsilon}$ and $\sigma_{\zeta}$. Thus, this extra wage target is important in matching both first and second moments when analyzing wage inequality in the model.

\subsection{Firm-Specific Parameters}

There are four parameters associated with the firm that must be pinned down in 1980, along with two time trends.

Time invariant firm parameters. Two parameters are set outside the estimation procedure. More precisely, the parameter $\nu$ is set within the range of standard estimate for college to non-college labor elasticities (see Autor et al., 1998, 2008), and the share parameter on human capital is normalized, $\lambda=0.5$.

The parameters $\alpha$ and $\rho$ are pinned down by matching the share of college graduates (age 25 to 30) in 1980 and the college wage premium in 1980. The resulting elasticity parameter is in line with estimates in Appendix B, $\rho=0.707 .{ }^{11}$

\footnotetext{
${ }^{10}$ Stinebrickner \& Stinebrickner (2013) find that 45 percent of the college dropout rate at Berea College (a small liberal arts college in Kentucky) can be explained by students learning their academic performance in the first two years of college.

${ }^{11}$ Alternatively, using the ACS data, but instead computing elasticities across occupations rather than time, as in Appendix B, yields similar results as the calibration, with the interval of plus/minus one standard suggesting $\rho \in[0.33,0.72]$. However, since this method is subject to various assumptions related
} 
Time trends. Given the definition of SBTC and MBTC, we normalize $A$ and $M$ to one in 1980. By definition, a rise in $A_{t}$ will affect both the returns to college ability and math equally, but a rise in $M_{t}$ will only increase the returns to math. We restrict the growth rate of SBTC such that $\gamma_{a, t} \in[0.018,0.028]$, which follows from the range of estimates found in Table 2 of Autor et al. (2008). The two growth rates are then calibrated to match the rise in the share of college graduates from 1980 to 2010, along with the rise in the college wage premium. This process yields a SBTC growth rate of $\gamma_{a}=0.027$ per annum, which lies at the upper range of possible estimates. As relatively high SBTC decreases the effect of MBTC (Section 3.4), the SBTC growth rate estimate is conservative. The calibration suggests that MBTC is substantial during this time period, with $\gamma_{m}=0.043$. We present a counterfactual is Section 5.1 to understand how important this precise value of $\gamma_{m}$ is for the model.

\subsection{Calibration Summary}

Table 2 summarizes the estimated and calibrated parameters, with estimated parameters above the center line and calibrated parameters at the bottom.

The 1980 data targets used in pinning down the calibrated parameters are summarized in Table 3. The model does well in matching all targets. It only slightly overpredicts the average ability of college graduates and the C90-C50 wage differential of college graduates. For the time trends, the model is unable to match the full rise in the share of college graduates by 2010 . However, the model is able to match the share of new college graduates in 2010. This discrepancy can be explained by the draft during the Vietnam War generating above average college graduation rates (Lemieux \& Card, 2001).

to the computation of relative wage returns, efficiency units and grouping of occupations, our preferred estimate is using the calibrated elasticity. 
Table 2: Calibration Summary

\begin{tabular}{ccl} 
Parameter & Value & Source / Type \\
\hline$\beta$ & 0.9 & standard discounting \\
$N$ & 9 & retirement at 63 (5 year periods) \\
$\sigma_{\eta}$ & 0.367 & transitory wage luck (Guvenen \& Kuruscu, 2010) \\
$\theta^{i}$ & $\sim N\left(0, \sigma_{\theta}^{2}\right)$ & initial ability NLSY79 \\
$\nu$ & 0.597 & elasticity parameter: college to non-college (Autor et al., 2008) \\
$\lambda$ & 0.5 & ability share parameter - normalized \\
$A_{0 t}$ & 1.0 & SBTC 1980 - normalized \\
$M_{0 t}$ & 1.0 & MBTC 1980 - normalized \\
\hline$\sigma_{\theta}$ & 0.142 & initial ability \\
$\hat{\mu}_{\epsilon}$ & 0.229 & overconfidence \\
$\sigma_{\epsilon}$ & 0.205 & unknown ability component \\
$\sigma_{\zeta}$ & 0.042 & utility of studying \\
$\delta_{0}$ & -2.953 & zero math outcome \\
$\delta_{1}$ & 2.769 & math skill slope \\
$\bar{h}$ & 0.109 & minimum college requirement \\
$\bar{m}$ & 0.625 & maximum math credits \\
$\alpha$ & 0.411 & college share parameter \\
$\rho$ & 0.707 & elasticity parameter: ability to math \\
$\gamma_{a}$ & 0.027 & SBTC growth rate \\
$\gamma_{m}$ & 0.043 & MBTC growth rate \\
\hline
\end{tabular}

Table 3: Targets Summary

\begin{tabular}{lcc} 
Target & Data $(1980)$ & Model \\
\hline Fraction 0 Math Credits & 0.113 & 0.113 \\
Fraction 21 Math Credits & 0.118 & 0.118 \\
College Dropout Rate & 0.550 & 0.548 \\
corr $(\theta, h)$ & 0.400 & 0.401 \\
$\theta_{\text {college graduate }}$ & 0.805 & 0.821 \\
$\theta_{\text {non-college worker }}$ & -0.282 & -0.275 \\
C90-C50 & 0.568 & 0.579 \\
C90-C10 & 1.174 & 1.154 \\
NC90-NC10 & 1.104 & 1.072 \\
\hline College Wage Premium & 0.247 & 0.247 \\
Young College Graduates & 0.241 & 0.247 \\
\hline 2010 College Graduates & 0.301 & 0.281 \\
2010 College Wage Premium & 0.493 & 0.495 \\
\hline
\end{tabular}


Table 4: US Wage Inequality \& Model Results

\begin{tabular}{|c|c|c|c|c|}
\hline & \multirow[b]{2}{*}{ Year } & \multicolumn{3}{|c|}{ Relative Log Wages } \\
\hline & & $90-10$ & $90-50$ & $50-10$ \\
\hline \multicolumn{5}{|l|}{ All } \\
\hline \multirow[t]{2}{*}{ Data } & 1980 & 116 & 55 & 62 \\
\hline & 2010 & 150 & 77 & 73 \\
\hline \multirow[t]{2}{*}{ Model } & 1980 & 112 & 55 & 57 \\
\hline & 2010 & 126 & 67 & 59 \\
\hline$\%$ Explained & & 42 & 52 & 23 \\
\hline \multicolumn{5}{|l|}{ College } \\
\hline \multirow[t]{2}{*}{ Data } & 1980 & $117^{*}$ & $57^{*}$ & 61 \\
\hline & 2010 & 145 & 74 & 72 \\
\hline \multirow[t]{2}{*}{ Model } & 1980 & $118^{*}$ & $59^{*}$ & 58 \\
\hline & 2010 & 144 & 71 & 73 \\
\hline$\%$ Explained & & 92 & 68 & 131 \\
\hline
\end{tabular}

\section{Results}

The model accurately captures a variety of inequality dynamics, including part of the general wage trends and all of the intra-college group wage decomposition between 1980 and 2010. These results are driven by the introduction of MBTC into a standard SBTC framework. The counterfactual presented in Section 5.1 confirms that MBTC must be present in order to match the wage trends of college graduates at both the top and bottom deciles.

The rise in the fraction of college graduates and the college wage premium are matched by construction. Table 4 compares the total US inequality trends and the modeled results. The base model explains close to half of the rise in inequality of the aggregate US male population.

The model's strength lies in explaining intra-college income inequality, given that MBTC only impacts educated individuals. The model explains almost all the trends for college graduates, both at the top and bottom. At the other end of the income distribution, none of the aggregate non-college trends, NC90-NC10, NC-90-NC50 and NC50-NC10, are 


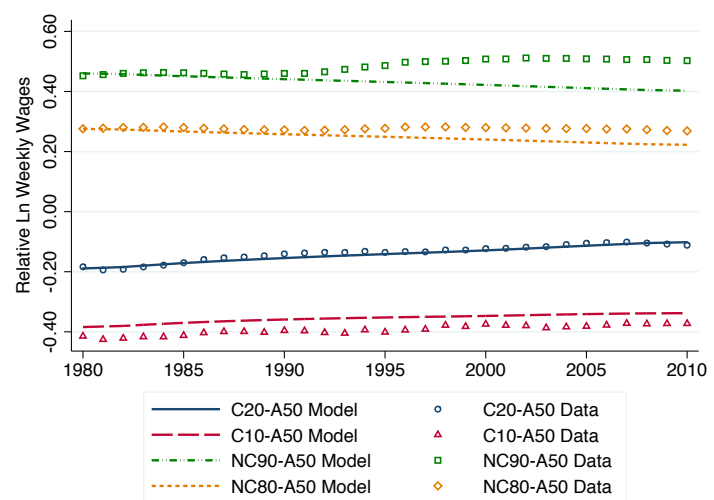

(a) Bottom

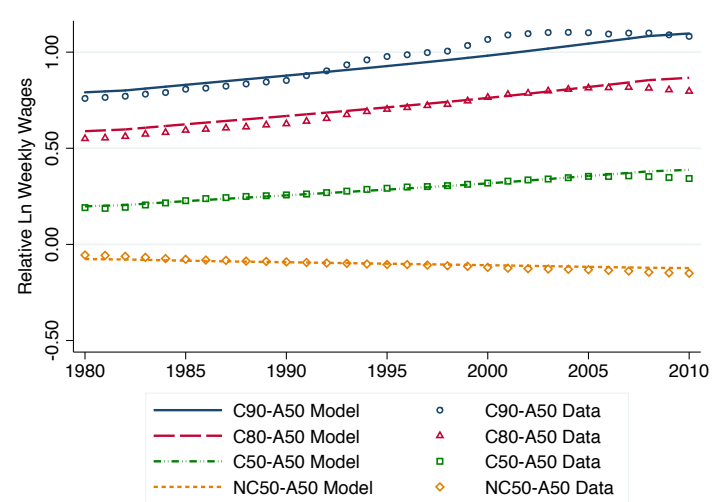

(b) Top

Figure 11: Model Wage Trend Decomposition

well explained.

The detailed decompositions in Figures 11 provide the answer to why the increase in wage inequality within the non-college group is not generated by the model. The model matches the NC80-A50 and NC50-A50 wage evolution, but it predicts a slight fall in both the NC90-A50 and a large fall in the NC10-A50 percentile (not pictured). In contrast, the data shows a mild increase in the NC90-A50 relative wage and a decrease in the NC10-A50 relative wage. That is, the model is able to replicate the average uneducated worker's wage, but not the extremes. These unmatched trends are unsurprising, as the model ignores the human capital accumulation of uneducated individuals (e.g., dropping out of high school or completing vocational 2-year college programs) and MBTC only affects college labor directly. Therefore, the model is more suited to predict income trends within the top half of the distribution, which includes all college graduates. Both Figures 11a and 11b show an almost perfect matching of the the college distribution across the top (C90-A50, C80-A50), average (C50-A50), and the bottom (C20-A50, C10-A50) deciles.

Initial ability. The NLSY79 and NLSY97 show that ex ante ability, as measured by the AFQT of college graduates, has fallen from 0.805 to 0.775 . Since individuals were aged 12 to 16 in the NLSY97 sample, the natural comparison of college cohorts in the model is 
2000-2005. The model slightly overpredicts the average initial ability in 1980 and predicts a fall to 0.769 by 2000 and 0.754 by 2005 . While the fall is slightly larger than observed from the NLSY79 to NLSY97, the estimates are close to suggest that the model is not generating the above wage trends through an incorrect composition of college graduates.

Dropout rate. The model generates a rise in the college dropout rate from the matched target of 55 percent in 1980 to 59 percent by 2010. Bound et al. (2010) show that the non-completion rate for males aged 25 went from about 55 percent in 1980 to about 60 percent in 2000. By the year 2000 the model generates a dropout rate of 58 percent, just shy of the data estimates.

College math credits (0 and 21). The model shifts each subsequent cohort towards lower college math levels. In the 1960 cohort 11.3 percent of college graduates (in both the data and model) had zero math credits. By the 1980 cohort this number had risen to 14.9 percent in the data and 14.8 percent in the model. Looking at the fraction of individuals with 21 credits or more, the data falls from 11.8 percent for the 1960 cohort to 10.0 percent for the 1980 cohort. The model replicates just over one-third of this drop, generating a fall from 11.8 to 11.1 percent from 1980 to 2010 for new college graduates.

College majors. Figures 7 and 12 compare the share of college graduates over all math outcomes ("college majors"). As math is a continuous variable within the model, the figure is computed by scaling all math outcomes such that the maximum possible credits is 21 , and then rounded up to the nearest three credit equivalent. The model, using a simple math technology, does well in matching the overall shape and evolution of college graduates over math outcomes. However, the continuous math outcome variable in the model leads to a smaller mass around three credits compared to the data. It should be noted that a large share of college majors might only require three math credits to graduate, suggesting a kink in the college math "production function." Since the model studies aggregates at 


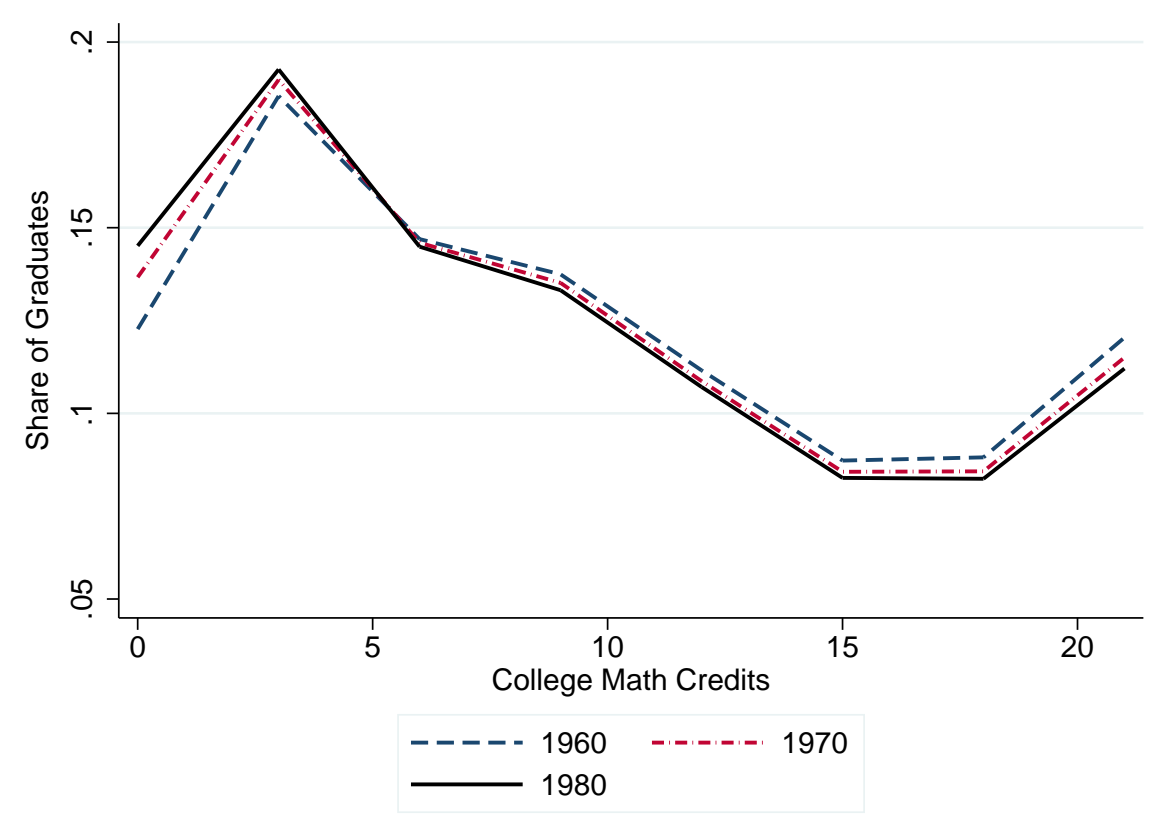

Figure 12: College Major Graduation Share by Cohorts

the top and bottom of the wage distribution, this is not of first order importance for the results.

\subsection{Counterfactual}

We assess the importance of the returns to math by setting $\gamma_{m, t}=0$. The removal of the MBTC mechanism clearly reveals the contribution of the returns to acquired math skill. The counterfactual model predicts more individuals attempting college, with a college dropout rate of 60.4 percent in 2010, but also more individuals graduating from college, with the share of college graduates increasing to 28.6 percent in 2010 from 28.1 percent in the benchmark model. The share of zero-math credit graduates increases to 15.9 percent and the share of individuals with 21 credits decreases to 10.8 percent by 2010 . Simultaneously, the average quality of a college graduate drops from 0.744 to 0.712 in terms of initial ability.

Table 5 compares the 2010 wage inequality levels between the data, the benchmark 
Table 5: US Wage Inequality \& Counterfactual Results

\begin{tabular}{lcccc} 
& & \multicolumn{3}{c}{ Relative Log Wages } \\
\cline { 3 - 5 } & Year & $90-10$ & $90-50$ & $50-10$ \\
\hline All & & & & \\
Data & 2010 & 150 & 77 & 73 \\
SBTC + MBTC & 2010 & 126 & 67 & 59 \\
SBTC & 2010 & 129 & 68 & 62 \\
\hline \% SBTC Explained & & 51 & 55 & 42 \\
\hline College & 2010 & 145 & 74 & 72 \\
Data & 2010 & 144 & 71 & 73 \\
SBTC + MBTC & 2010 & 118 & 60 & 58 \\
SBTC & & 3 & 4 & 1 \\
\hline \% SBTC Explained & & & & \\
\hline
\end{tabular}

model and the counterfactual model results, omitting the 1980 values, as they are identical to Table 4 by construction. At an aggregate level, the counterfactual model is marginally better than the benchmark model in matching broad income inequality trends, particularly at the bottom of the wage distribution. However, these broad measurements hide the intracollege inequality trends that are ignored by the counterfactual model. The second part of Table 5 shows that the counterfactual model is unable to match any of the trends in wage inequality between college graduates, explaining only one to four percent of the rise in inequality from 1980 to 2010 .

Figure 13 further highlights how the counterfactual model matches the aggregated income inequality trends for the wrong reasons. The counterfactual predicts a sharp increase in wages for the bottom college deciles and a sharp fall for wages of the top non-college deciles. This first point is driven by higher returns to the general human capital of college graduates (relative to math). The non-college results are driven by composition. That is, more low ability students enter and graduate from college, effectively decreasing the ability of the top non-college deciles.

The mechanisms of SBTC and MBTC work in opposite directions for the bottom of the college distribution. SBTC alone benefits all college graduates in wage terms. The bottom deciles, in particular, gain compared with the average individual in the economy. 


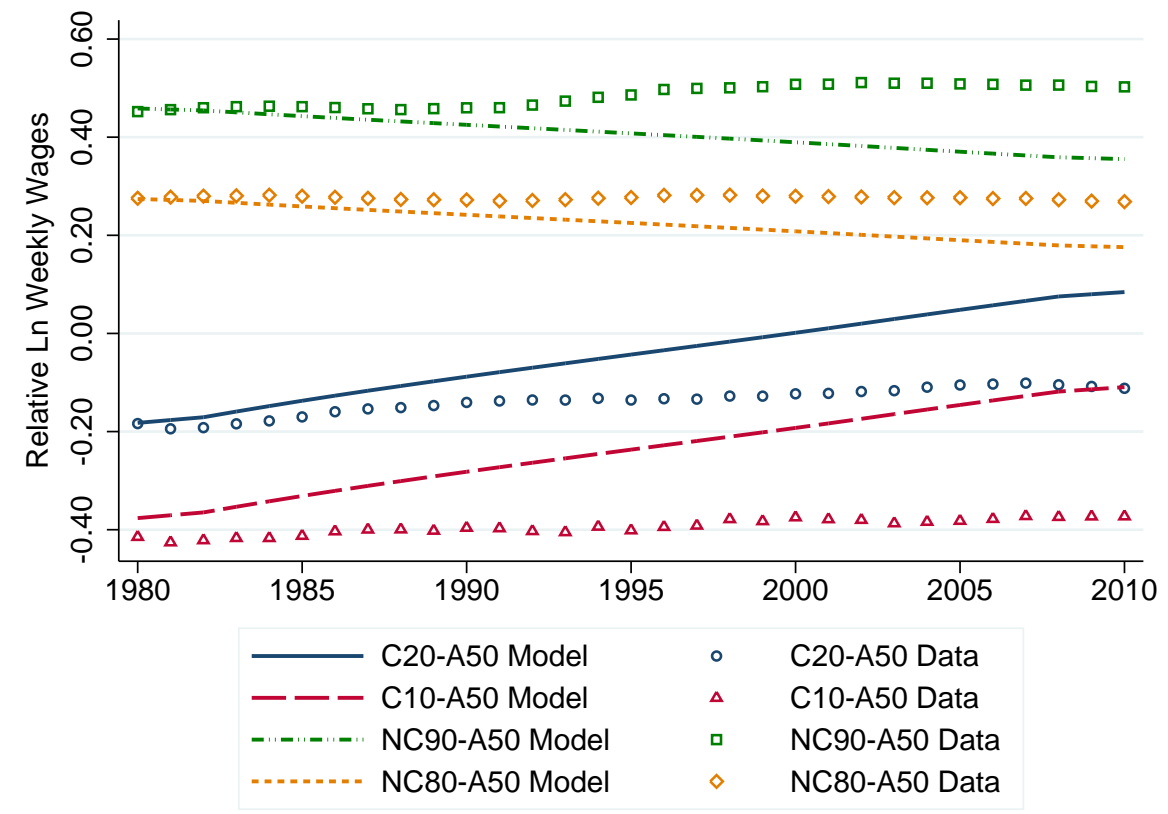

Figure 13: US Wage Inequality \& Counterfactual Results

Further highlighting the broad power of the SBTC mechanism, the counterfactual pushes the income of the $\mathrm{C} 20$ group above the A50 wage, while the $\mathrm{C} 10$ wage approaches parity with the A50 wage. In contrast, MBTC is effective at only increase the top income deciles, leaving the bottom deciles with decreasing or stagnant wages. Thus, only the combination of these two different technical change concepts can generate the observed wage inequality trends of the US male college graduate population, along with part of the divergence in wages across the entire US male population.

\section{Conclusion}

This paper studies the role of math in determining both inter- and intra-education group wage inequality. The connection between ex ante math abilities, college math, and the labor demand for math skills provides a simple and powerful mechanism, explaining a large component of male wage inequality in the US. The estimated structural model 
highlights the importance of MBTC in explaining both aggregate wage inequality and the wage trends at the extremes of the college distribution. The model is also able to generate average trends for both college and non-college groups, closely matching the general trends achieved by SBTC alone.

Given the results, there a number of interesting research extensions. As we extend the research on the determinants of wage inequality from a post-education perspective (Kambourov \& Manovskii, 2009; Huggett et al., 2011) to a pre-college education perspective, we assume initial math ability is determined prior to college. Given the central role of math, studying the origins of initial math skills is of primary importance in determining college math outcomes and is a natural first extension of the MBTC mechanism presented here. A second research extension focuses on the gender dimension of education choices to investigate the characteristics of the college majors favored by women. While men optimize their education choices to maximize pecuniary outcomes and choose high-math college majors given initial ability constraints, women exhibit more complex preferences with respect to non-pecuniary outcomes that seem to distort the education decision. In ongoing work, we study women's college decisions in a life-cycle model that accounts for atrophy and repair of skills due to career breaks. 


\section{References}

Acemoglu, D. (2002). Technical Change, Inequality, and the Labor Market. Journal of Economic Literature, 40(1), 7-72.

Altonji, J. G., Bharadwaj, P., \& Lange, F. (2012). Changes in the Characteristics of American Youth: Implications for Adult Outcomes. Journal of Labor Economics, 30(4), $783-828$

Altonji, J. G., Blom, E., \& Meghir, C. (2012). Heterogeneity in Human Capital Investments: High School Curriculum, College Major, and Careers. Annual Review of Economics, 4(1), 185-223.

Arcidiacono, P., Hotz, V. J., \& Kang, S. (2012). Modeling College Major Choices using Elicited Measures of Expectations and Counterfactuals. Journal of Econometrics, $166(1), 3-16$.

Autor, D. H., Katz, L. F., \& Kearney, M. S. (2008). Trends in U.S. Wage Inequality: Revising the Revisionists. The Review of Economics and Statistics, 90(2), 300-323.

Autor, D. H., Katz, L. F., \& Krueger, A. B. (1998). Computing Inequality: Have Computers Changed The Labor Market? The Quarterly Journal of Economics, 113(4), $1169-1213$.

Bailey, M. J. \& Dynarski, S. M. (2011). Gains and Gaps: Changing Inequality in U.S. College Entry and Completion. NBER Working Papers 17633, National Bureau of Economic Research, Inc.

Bartel, A. P. \& Lichtenberg, F. (1987). The Comparative Advantage of Educated Workers in Implementing New Technology. The Review of Economics and Statistics, 69(1), 1-11.

Bordalo, P., Gennaioli, N., \& Shleifer, A. (2014). Stereotypes. NBER Working Papers 20106, National Bureau of Economic Research. 
Bound, J., Lovenheim, M. F., \& Turner, S. (2010). Why Have College Completion Rates Declined? An Analysis of Changing Student Preparation and Collegiate Resources. American Economic Journal: Applied Economics, 2(3), 129-57.

Carneiro, P., Heckman, J. J., \& Vytlacil, E. J. (2011). Estimating Marginal Returns to Education. American Economic Review, 101(6), 2754-81.

Eisenhauer, P., Heckman, J. J., \& Mosso, S. (2013). Estimation of Dynamic Discrete Choice Models by Maximum Likelihood and the Simulated Method of Moments. Technical report.

Guvenen, F. \& Kuruscu, B. (2010). A Quantitative Analysis of the Evolution of the U.S. Wage Distribution, 1970-2000. In NBER Macroeconomics Annual 2009, Volume 24, NBER Chapters (pp. 227-276). National Bureau of Economic Research.

Hansen, G. (1993). The Cyclical and Secular Behaviour of the Labour Input: Comparing Efficiency Units and Hours Worked. Journal of Applied Econometrics, 8(1), 71-80.

Heckman, J. J. \& Mosso, S. (2014). The Economics of Human Development and Social Mobility. Working Paper 19925, National Bureau of Economic Research.

Hendricks, L. \& Schoellman, T. (2014). Student Abilities During the Expansion of US Education. Journal of Monetary Economics, 63, 19-36.

Huggett, M., Ventura, G., \& Yaron, A. (2011). Sources of Lifetime Inequality. American Economic Review, 101(7), 2923-54.

Kambourov, G. \& Manovskii, I. (2009). Occupational Mobility and Wage Inequality. Review of Economic Studies, 76(2), 731-759.

King, M., Ruggles, S., Alexander, J. T., Flood, S., Genadek, K., Schroeder, M. B., Trampe, B., \& Vick, R. (2010). Integrated Public Use Microdata Series, Current Population Survey: Version 3.0. [Machine-readable database]. Minneapolis: University of Minnesota. 
Krusell, P., Ohanian, L. E., Ríos-Rull, J.-V., \& Violante, G. L. (2000). Capital-Skill Complementarity and Inequality: A Macroeconomic Analysis. Econometrica, 68(5), $1029-1054$.

Lemieux, T. \& Card, D. (2001). Going to College to Avoid the Draft: The Unintended Legacy of the Vietnam War. American Economic Review, 91(2), 97-102.

Paglin, M. \& Rufolo, A. M. (1990). Heterogeneous Human Capital, Occupational Choice, and Male-Female Earnings Differences. Journal of Labor Economics, 8(1), 123-44.

Rothstein, J. M. (2004). College Performance Predictions and the SAT. Journal of Econometrics, 121(1-2), 297-317.

Silos, P. \& Smith, E. (2012). Human Capital Portfolios. Working Paper 2012-03, Federal Reserve Bank of Atlanta.

Stinebrickner, R. \& Stinebrickner, T. R. (2014). A Major in Science? Initial Beliefs and Final Outcomes for College Major and Dropout. Review of Economic Studies, 81(1), $426-472$.

Stinebrickner, T. \& Stinebrickner, R. (2013). Academic Performance and College Dropout: Using Longitudinal Expectations Data to Estimate a Learning Model. NBER Working Papers 18945, National Bureau of Economic Research.

Storesletten, K., Telmer, C. I., \& Yaron, A. (2001). How Important Are Idiosyncratic Shocks? Evidence from Labor Supply. American Economic Review, 91 (2), 413-417.

Zafar, B. (2013). College Major Choice and the Gender Gap. Journal of Human Resources, $48(3), 545-595$. 


\section{A Data Appendix: Aptitude Measures}

This appendix lists the definition of the three DOT variables referenced in the paper. The three aptitude variables used are from the DOT 1977 and 1991 editions. We are unable to use the DOT successor, the Occupational Information Network (O*net), due to a measurement discontinuity in the recorded aptitudes.

In general, aptitudes measure the ability an individual must possess in order to perform a job successfully. More precisely, the measure is a function of the share in the population that meets this ability level. That is, there are five categories: (1) the bottom 10 percent of the population, (2) the bottom third excluding the bottom 10 percent , (3) the middle third, (4) the top third excluding the top 10 percent, and (5) the top 10 percent. We translate these measures to a scale ranging from zero to one, e.g., an aptitude above 0.66 would correspond to an individual in the top-third of the population.

Out of the 11 measures reported in the DOT 1977 and 1991, we use the three measures: general, numerical and verbal ability.

- General ability is the ability to understand instructions, understand principles and to make judgments. It encompasses a number of skills, e.g., using logic and scientific thinking, understanding procedures, establishing facts and drawing conclusions, etc. This measure is highly correlated with the ability to perform well in school.

- Numerical aptitude is the ability to perform arithmetic. The complexity and speed of operations is taken into account when assigning the category.

- Verbal aptitude is the ability to understand and use language effectively. Both oral and written skills, including the use of technical terminology, are taken into account when assigning categories for each occupation. 


\section{B Empirical Appendix: Estimating MBTC Over Time}

Figure 4 graphs the relative wage rates between high-math college and non-college occupations, and low-math college and non-college occupations. Relative wages are normalized to zero in 1974 for easy comparison of the two MBTC and SBTC trends.

Relative labor supplies and, consequently, relative wages rates, are computed following Hansen (1993) in estimating labor efficiency units at time $t$ as,

$$
L_{j t}^{E}=\sum_{k} \psi_{k} L_{j t, k}
$$

where $L_{j t, k}$ is the total labor supply of group $k$ of labor type $j=\{u, e, m e\}$ (non-college $(\mathrm{u})$, low-math college labor (e) and high-math labor (me)), and $\psi_{k}$ is the group's weight. Weights are determined by,

$$
\psi_{k}=\frac{\bar{\omega}_{k}}{\bar{\omega}}
$$

the average log weekly wage of group $k$ over the average wage of the entire population (across individuals over the entire time period). Groups are made up of a given five-year birth cohort, sex and education group (high school dropout, high school graduate, some college, college graduate, and post-graduate).

Using this definition of efficiency units of labor, log relative wage rates are,

$$
\ln \left(w_{j t}\right)-\ln \left(w_{u t}\right)=\sum_{k} f_{j t, k} \frac{\omega_{j t, k}}{L_{j t}^{E}}-\sum_{k} f_{u t, k} \frac{\omega_{u t, k}}{L_{u t}^{E}} \text { for } j=e, m e
$$

where $f_{j t, k}$ is the fraction of group $k$ of labor type $j$ individuals in the economy each period.

\section{B.1 Quantifying MBTC versus SBTC}

Given wage rates and relative labor supplies, we can quantify the difference between SBTC and MBTC as captured in Figure 4.

Analogous to the firms problem in Section 3, we define a nested-CES between the three 
types of labor $j=\{u, e, m e\}$,

$$
Y_{t}=\left[\alpha L_{u t}^{\nu}+(1-\alpha)\left[\lambda\left(A_{t} L_{e t}\right)^{\rho}+(1-\lambda)\left(A_{t} M_{t} L_{m e t}\right)^{\rho}\right]^{\frac{\nu}{\rho}}\right]^{\frac{1}{\nu}},
$$

with SBTC (labor augmenting technology for all college graduates equally) as, $A_{t}=(1+$ $\left.\gamma_{a t}\right) A_{t-1}$ and MBTC (labor augmenting technology for high-math labor only) as, $M_{t}=$ $\left(1+\gamma_{m t}\right) M_{t-1}$.

From the firm's cost minimization problem, we obtain two relative wage equations,

$$
\begin{aligned}
& \ln \left(\frac{w_{e t}}{w_{u t}}\right) \approx \\
& C+(\nu-1) \ln \left(\frac{L_{e t}}{L_{u t}}\right)+\nu \ln \left(A_{t}\right)+\frac{1-\lambda}{\lambda} M_{t}^{\rho}\left(\frac{\nu-\rho}{\rho}\right)\left(\frac{L_{m e t}}{L_{e t}}\right)^{\rho}
\end{aligned}
$$

and

$$
\begin{aligned}
& \ln \left(\frac{w_{m e t}}{w_{u t}}\right) \approx \\
& C+(\nu-1) \ln \left(\frac{L_{m e t}}{L_{u t}}\right)+\nu \ln \left(A_{t}\right)+\nu \ln \left(M_{t}\right)+\frac{\lambda}{1-\lambda}\left(\frac{1}{M_{t}}\right)^{\rho}\left(\frac{\nu-\rho}{\rho}\right)\left(\frac{L_{e t}}{L_{m e t}}\right)^{\rho} .
\end{aligned}
$$

Equation (B.5) shows the college premium of low-math college graduates relative to noncollege labor, and Equation (B.6) shows the relationship between high-math college graduate wages and non-college wage returns. As in Krusell et al. (2000), we can analyze the growth in relative wages using these two equations, assuming $\lambda=1-\lambda$,

$$
g_{w_{e t}}-g_{w_{u t}}=(\rho-1) g_{L_{e t}}-(\nu-1) g_{L_{u t}}+\nu g_{A_{t}}+(\nu-\rho)\left(g_{L_{m e t}}+g_{M_{t}}\right)
$$

and

$$
g_{w_{m e t}}-g_{w_{u t}}=(\rho-1) g_{L_{m e t}}-(\nu-1) g_{L_{u t}}+\nu g_{A_{t}}+\rho g_{M_{t}}+(\nu-\rho) g_{L_{e t}} \text {. }
$$


Table 6: College-Labor CES

\begin{tabular}{|c|c|c|}
\hline Variable & Coefficient & (Std. Err.) \\
\hline Time & $0.002^{* *}$ & $(0.000)$ \\
\hline Labor Supply & $-0.274^{*}$ & $(0.104)$ \\
\hline Intercept & -0.035 & $(0.066)$ \\
\hline $\mathrm{N}$ & \multicolumn{2}{|c|}{37} \\
\hline $\mathrm{R}^{2}$ & \multicolumn{2}{|c|}{0.821} \\
\hline
\end{tabular}

With the two Equations (B.7) and (B.8) we can compute the two unknowns of interest, $g_{A_{t}}=\gamma_{a t}$ and $g_{M_{t}}=\gamma_{m t}$.

Having computed efficiency units of labor and relative wages rates from the CPS 1974 to 2010, all that remains is pinning down the elasticities between college and non-college labor, $\frac{1}{1-\nu}$, and between low- and high-math labor, $\frac{1}{1-\rho}$. The parameter $\nu=0.597$ is set as in the simulation (see Section 4). However, $\rho$ used here is not directly comparable with the parameter from Section 3. Therefore, in the appendix we estimate $\rho$ using CPS data.

The firm's nested-CES minimization problem provides the following relative wage equation,

$$
\ln \left(w_{m e t}\right)-\ln \left(w_{e t}\right)=\ln \left(\frac{(1-\lambda)}{\lambda}\right)+\rho \ln \left(M_{t}\right)+(\rho-1) \ln \left(\frac{L_{m e t}}{L_{\text {het }}}\right)
$$

Assuming a linear time trend for $\ln \left(M_{t}\right)$, we can estimate this equation using relative wages and efficiency units of labor to obtain $\rho$. Table 6 summarizes the results. The parameter $\rho=0.726$ is significant at five percent. ${ }^{12}$ In contrast, the equivalent regression for noncollege labor suggests perfect substitution between low- and high-math uneducated labor. This is also consistent with the findings of Figure $2 b$.

With the elasticity parameters, $\rho=0.726$ and $\nu=0.597$, we can compute the growth in $A_{t}$ and $M_{t}$ to be consistent with the growth in relative wages of non-college/college and low-/high-math labor, given the growth in efficiency units from the CPS during 1974 to 2010 .

\footnotetext{
${ }^{12}$ The elasticity is not sensitive to the precise partitioning of low- and high-math occupations. For example, splitting the sample by the the top-third versus bottom two-third yields similar results.
} 
Using the whole time period, this simple accounting exercise suggests that $\gamma_{e t}=0.021$ and $\gamma_{m e t}=0.003$. That is, MBTC is positive and larger than zero. To put this value into perspective, comparing $A_{t}$ versus $A_{t} \times M_{t}$, the growth rates suggest that labor augmenting technical change on high-math occupations grew about 16 percent per annum faster than on low-math occupations.

For robustness, using $\rho$ of plus/minus one standard deviation, $\rho=0.621$ and $\rho=$ 0.830 , the relative growth of $A_{t} \times M_{t}$ is 14 and 17 percent larger, respectively. The more complimentary the two types of college labor, the smaller MBTC needs to be to match the relative wage growth of both low- and high-math labor to non-college labor. 